\title{
Operation Strategy for Hydrogen Production by Water Electrolysis Powered by Solar Photovoltaic Energy
}

\author{
E. Amores ${ }^{1}, J_{\text {. Rodríguez }}{ }^{1}$ and J. Oviedo ${ }^{1}$ \\ ${ }^{1}$ Centro Nacional del Hidrógeno $(\mathrm{CNH} 2)$ \\ Prolongación Fernando El Santo s/n, 13500 Puertollano (Ciudad Real, Spain) \\ Phone number: +0034 926 420682, e-mail: ernesto.amores@cnh2.es, jesus.rodriguez@cnh2.es
}

\begin{abstract}
Combination of alkaline water electrolysis with renewable energy sources can be one of the most sustainable strategies for $\mathrm{H}_{2}$ production. However, solar and wind energy sources are strongly dependent on weather conditions, which can cause fluctuations of power supplied to the electrolyzer. This variability usually involves some problems related with increments of the void fraction, generation of explosive mixtures or reduction in the efficiency. In order to limit these effects and to reduce the required voltage in the electrolysis, an optimized operation strategy is proposed in this study based on pumping flow according to the current supplied to the electrolysis cell. To this aim, a mathematical model including influence of different operation variables as electrodes distance, temperature and electrolyte flow rate has been developed and used as optimization tool. The obtained results confirm the convenience of the selected strategy, especially when the electrolyzer is powered by RREE.
\end{abstract}

\section{Key words}

Hydrogen Production, Water Electrolysis, Modelling, Solar PV Energy, Energy Storage.

\section{Introduction}

The increasing energy demand, the environmental impact and the dependence of oil producer countries are some of the most important problems which characterize the actual fossil fuel-based energy and transportation system.

In contrast to the problems associated with fossil fuels, renewable energy sources (RREE) represent the most promising and sustainable alternative for reaching a change in the global energetic model. However its inherent dependence on weather conditions causes them to be intermittent and so adequate energy storage technologies are required in order to improve the RREE performance.

In this context, hydrogen offers a promising solution. Excess electricity produced by RREE, can be converted into $\mathrm{H}_{2}$ by water electrolysis, stored and, when needed, it can be reconverted into electricity with fuel cells. Besides the energy vector for electricity, mobility and heat, $\mathrm{H}_{2}$ can also be utilized as a raw material for the chemical industry or further be used for the synthesis of various hydrocarbon fuels such as methane (Power-to-Gas technology) [1]-[3].

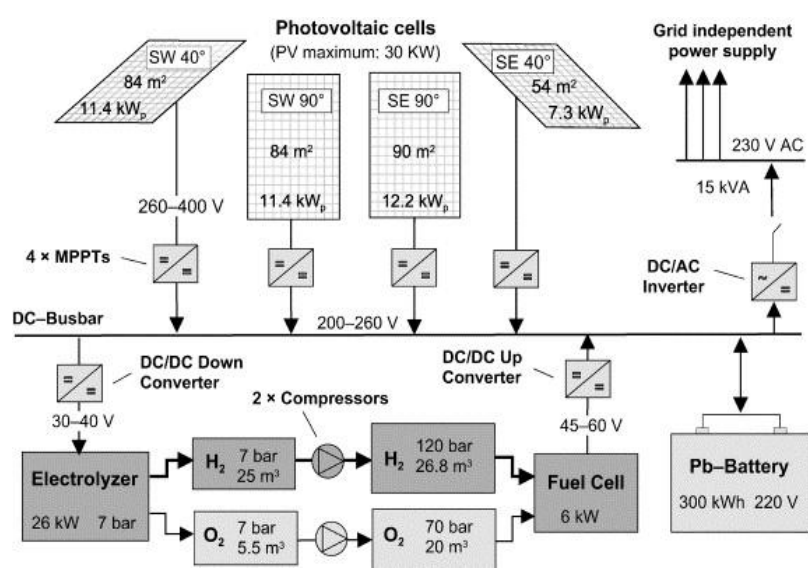

Fig. 1. Example of a system based on renewable energy using hydrogen as an energy vector (PHOEBUS project) [4].

Although $\mathrm{H}_{2}$ can be obtained by different ways, the "renewable energy-hydrogen" combination $\left(\mathrm{RREE}-\mathrm{H}_{2}\right)$ by water electrolysis is probably one of the most environmental friendly strategies (Fig. 1). For this reason, in the last decades, great attention on interaction RREE$\mathrm{H}_{2}$ was paid by energy companies and states, as evidenced by many demonstration projects as: HYSOLAR (1985), First (1990), PHOEBUS (1996), HARI (2001), Wind2H2 (2006), Res2h2 (2007) or ITHER (2008).

Among the different electrolysis technologies, the alkaline water electrolysis is optimal for large scale hydrogen production because it is an economic and mature technology [5]. Nonetheless, as wind and solar energy are highly dependent on weather conditions, the fluctuations of power supplied to an electrolyzer could cause different problems such as: generation of explosive mixtures, corrosion of materials, pressure drops and decreased efficiency, among many others.

According with different authors [6], [7], the high presence of bubbles in the anodic and cathodic compartments as consequence of gas generated during electrolysis, increases the ohmic drops, especially at high current and small distances between electrodes. Therefore the energy demand is higher and the efficiency of the electrolysis process decreases. 
In order to reduce these problems, a suitable and simple approach could be the optimization of the process by pumping flow. This enables the gas exits the electrolysis cell faster. This strategy could be especially suitable for the typical power supply fluctuations of RREE, because one could determine the optimal electrolyte flow depending of the solar irradiation or wind velocity, i.e. according to the amount of gas present in the cell.

In this context, mathematical modelling can be a useful strategy in order to achieve a properly design and operation of alkaline electrolyzers powered by RREE. Nowadays, the alkaline water electrolysis models usually used as reference is that reported by Ulleberg in 2003 [4]. However, although this model accurately reproduces electrochemical and thermodynamic effects, it does not include other important operation parameters, which can strongly influence in the electrolysis process. In order to improve this model, in a later work a modification of it was reported, including the influence of electrolyte concentration and electrode-membrane distance [8].

The present work reports a variation of the Ulleberg model, taking into account the influence of electrolyte flow, distance between electrodes, temperature and applied current, with the goal of proposing a methodology of operation when working with RREE. Using this model and taken into account the study carried out about the fluid dynamics in an alkaline electrolysis cell, it can be developed an additional approach to optimize the electrolyte flow rate depending on the current applied to the electrolyzer. In this way, it can be established an optimal operating strategy for $\mathrm{H}_{2}$ production when an electrolyzer is powered by renewable energies. In this paper, the results obtained are shown.

\section{Hydrogen Production by Electrolysis}

\section{A. Alkaline Water Electrolysis}

Alkaline water electrolysis is the decomposition of water into hydrogen and oxygen by passing an electric current (DC) between two electrodes separated by a high ionic conductivity electrolyte (usually 30-35 wt\% $\mathrm{KOH}$ aqueous solution). The theoretical fundamentals that explain this process are thermodynamics, kinetics of the reactions that occur at the electrodes and various transport phenomena involved in the electrolysis [4], [9]. The overall reaction is:

$$
\mathrm{H}_{2} \mathrm{O} \rightarrow \mathrm{H}_{2}+\frac{1}{2} \mathrm{O}_{2}
$$

For reaction (1) to occur a minimum voltage is required, which is known as reversible voltage $\left(\mathrm{U}_{\text {rev }}\right)$, which corresponds to $1.23 \mathrm{~V}$ at 1 bar and $25^{\circ} \mathrm{C}$. However, in practice, cell voltage $\left(\mathrm{U}_{\text {cell }}\right)$ is always higher than reversible voltage because of irreversibilities, so the cell voltage can be defined as the sum of reversible voltage and overpotentials $(\eta)$ :

$$
U_{\text {cell }}=U_{\text {rev }}+\sum \eta
$$

The term $\eta$ is the sum of activation, ohmic and concentration overpotentials [8], [10]:
1) Activation Overpotentials: Required energy to overcome activation energies of $\mathrm{H}_{2}$ and $\mathrm{O}_{2}$ formation reactions on the electrodes surfaces.

2) Ohmic Overpotentials: Sum of the electrical resistance of some components like electrodes, current collectors, etc.; and the transport resistance related to gas bubbles, ionic transfer in the electrolyte and resistivity of membrane.

3) Concentration Overpotentials: It is due to masstransport limitations occurring on the surface of electrodes at high currents.

These overpotentials can be analyzed through the polarization curve of an electrolysis cell, as shown in Fig. 2 . The curve models the reaction kinetics of water electrolysis and it establishes the most appropriate values of voltage and current to obtain higher efficiencies. Usually, alkaline electrolyzers operate between 400-600 $\mathrm{mA} / \mathrm{cm}^{2}$ and temperatures of $60-80{ }^{\circ} \mathrm{C}$.

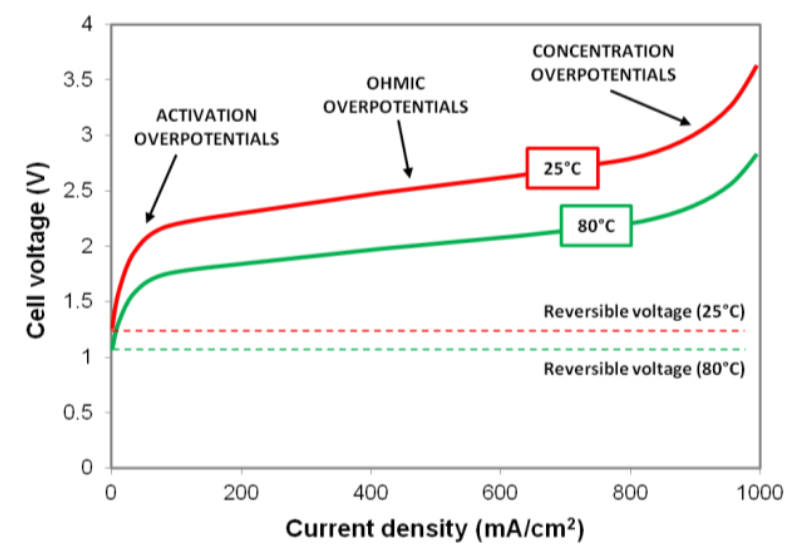

Fig. 2. Polarization curve of an alkaline electrolysis cell at different temperatures.

\section{B. Structure of an Alkaline Electrolysis Cell}

Fig. 3a shows a scheme of an alkaline electrolysis cell. The cell is filled with a $\mathrm{KOH}$ aqueous solution (electrolyte), where the hydroxyl ions $\left(\mathrm{OH}^{-}\right)$are responsible for ion transport. The electrodes (anode and cathode) are inside the cell and they are separated by a membrane that allows the flow of electric current but it is impermeable to gases. At the anode, oxygen bubbles are produced and at the cathode hydrogen is produced. These bubbles grow until they leave the electrode surface and rise up out of the electrolysis cell.

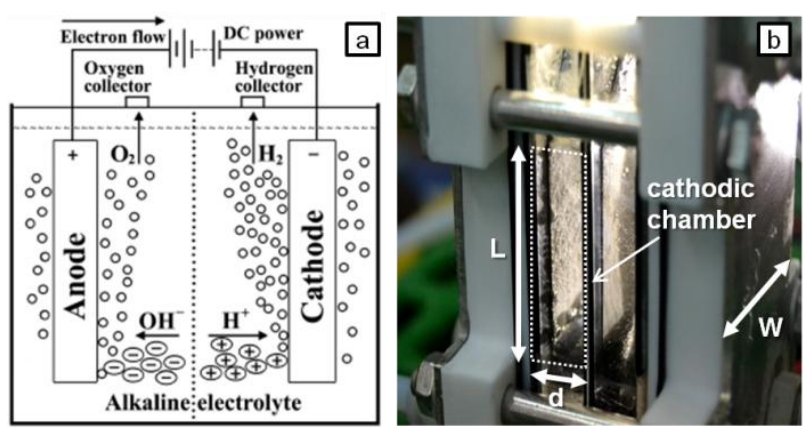

Fig. 3. Alkaline electrolysis cell: (a) cell scheme [11], (b) detail image of the electrolysis cell used in this study. 


\section{Polarization Curve Modelling Influence of Operation Parameters}

and

As noted above, the behaviour of an alkaline electrolysis cell depends on a number of complex processes that occur simultaneously. In this regard, electrolyzer modelling is a useful tool to study the different physical and chemical processes occurring during electrolysis, especially when an electrolyzer is powered by renewable energies. One of the most detailed models was proposed by Ulleberg [4]. This empirical model provides a basic form of the $\mathrm{i}-\mathrm{U}$ curve for a given operation temperature and it is able to simulate the behaviour of an alkaline electrolyzer [4]:

$$
U=U_{r e v}+r \cdot i+s \cdot \log (t \cdot i+1)
$$

According to (3), it can be observed that voltage "U" (V) needed for electrolysis at a specific electric current " $i$ " (A $\mathrm{m}^{-2}$ ), results from the sum of three different terms [4]: $U_{\text {rev }}$; the second component is related to ohmic overpotentials; and the third term corresponds to activation overpotentials. The influence of these overpotentials are taken into account by introducing the coefficients " $\mathrm{t}$ " $\left(\mathrm{m}^{2} \mathrm{~A}^{-1}\right)$ and "s" (V) correlated with activation overpotentials, and " $\mathrm{r}$ " $\left(\Omega \mathrm{m}^{2}\right)$ which corresponds to ohmic overpotentials. These parameters are defined in (5) and (6) in the next subsection. The term " $\mathrm{s}$ " is assumed as constant.

However, the mathematical model proposed by Ulleberg considers temperature as the only operational variable, assuming the rest of parameters as constants. Nevertheless, some authors have observed that forced convection improves the process because reduce mass transfer limitations and favour transport of bubbles [12]-[14]. Also, other authors have shown that distance between electrodes is strongly related to fluid dynamics of biphasic mixtures inside the cell and so with the efficiency [6]-[8], [15].

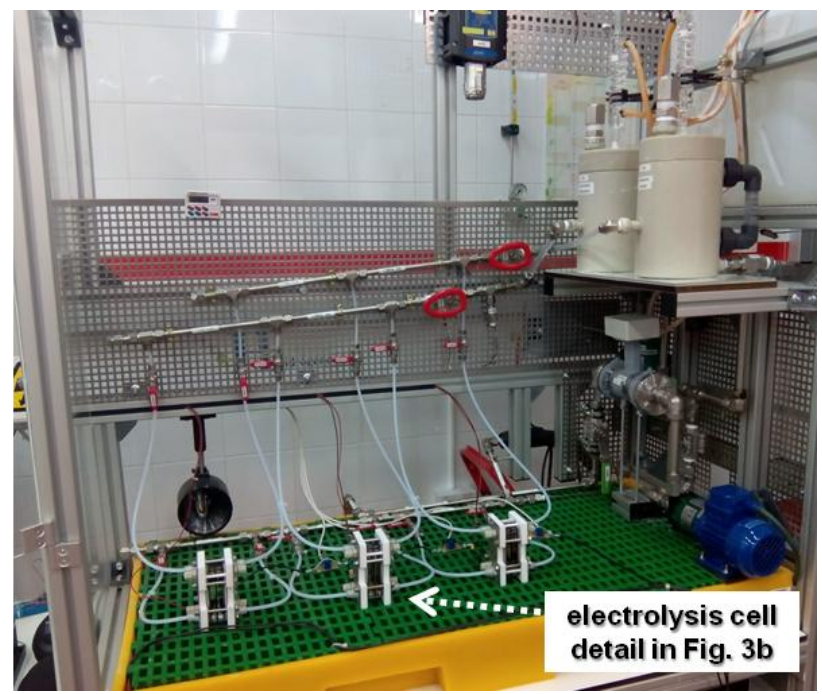

Fig. 4. Experimental facility used for develop the mathematical model proposed in this study.

In order to obtain a model which considers the influence of electrode-membrane distance and electrolyte flow rate, two new parameters have been incorporated into (3): "q" and " $z$ ".
Since both parameters have influence on the ohmic overpotentials, they may be added to the resistive term. Thus the next equation is proposed:

$$
U=U_{\text {rev }}+(r+q+z) \cdot i+s \cdot \log (t \cdot i+1)
$$

The values of the parameters " $q$ " and " $\mathrm{z}$ " depend on the electrode-membrane distance (d) and the electrolyte flow (Q) respectively as shown in (8) and (9). In order to determine these parameters and to analyze their influence on the electrolysis, different experiments were carried out in the experimental facility shown in Fig. 4. By this setup, wind or PV profiles can be simulated by a DC power supply. Fig. 3b shows a detail photograph of the alkaline electrolysis cell used in this study.

The studied variables in this paper were the temperature (between $\left.30-70^{\circ} \mathrm{C}\right)$, electrode-membrane distance $(0.9$, $1.5,4$ and $10 \mathrm{~mm}$ ) and electrolyte flow rate (from natural convection to $2.8 \mathrm{l} / \mathrm{min}$ ), according to a central composite design. These variables have been studied previously by different authors [7], [8], [13], [15]. In the following subsections the main results are shown.

\section{A. Influence of the Temperature}

The temperature is one of the most important operation parameters in the electrolysis [8], because as temperature increases, the required potential at a given current progressively decreases (Fig. 2). According to the model proposed by Ulleberg [4], the influence of temperature (T) can be determined by (5) and (6):

$$
\begin{aligned}
& r=r_{1}+r_{2} \cdot T \\
& t=t_{1}+\frac{t_{2}}{T}+\frac{t_{3}}{T^{2}}
\end{aligned}
$$

Where " $r_{1}$ ", " $r_{2}$ ", " $\mathrm{t}_{1}$ ", " $\mathrm{t}_{2}$ " and " $\mathrm{t}_{3}$ " are constants which can be obtained from experimental data.

\section{B. Influence of the Electrodes Distance}

The ohmic losses depend on the distance between electrode and membrane (d). It is especially relevant at high current and low flow rates. The obtained results show that there is an optimum electrode-membrane distance between 1.1-2.2 $\mathrm{mm}$ according to the applied current (Fig. 5a). Nagai et al. [7], [15] obtained a theoretical expression to calculate the optimal distance between membrane-electrode $\left(\mathrm{d}_{\mathrm{opt}}\right)$ of an cell, according to the temperature (T), current density (i), rise of gas $\left(\mathrm{u}_{\text {gas }}\right)$, height electrode $(\mathrm{L})$, pressure $(\mathrm{p})$, Faradays' constant $(\mathrm{F})$ and universal gas constant $(\mathrm{R})$ :

$$
d_{o p t}=\frac{1}{2} \cdot\left(1.27 \cdot \frac{R \cdot L}{F \cdot p} \cdot \frac{T}{u_{g a s}} \cdot i\right)
$$

In this investigation the optimal distance at natural convection is equal to $2.2 \mathrm{~mm}$ (at $50{ }^{\circ} \mathrm{C}$, electrode height $33 \mathrm{~mm}, 101325 \mathrm{~Pa}$ and $400 \mathrm{~mA} / \mathrm{cm}^{2}$ ). Using (7) and according to the experimental results, the following equation is proposed to model the effect of distance (d) on the ohmic overpotentials: 


$$
q=q_{1}+q_{2} \cdot\left|d-d_{\text {opt }}\right|
$$

Equation (8) shows a lineal relation between electrodemembrane distance (d) with the potential required in the electrolysis through the constants " $\mathrm{q}_{1}$ " and " $\mathrm{q}_{2}$ ". If the distance is greater than optimal distance $\left(\mathrm{d}_{\mathrm{opt}}\right)$, the potential decreases when electrode-membrane distance is also reduced (Fig. 5a). But, if the distance is lower than the " $\mathrm{d}_{\text {opt }}$ ", the potential demanded is increased because the gas produced is confined in the vicinity of the electrode.

\section{Influence of the Electrolyte Flow Rate}

According to Takeuchi et al. [12] forced convection clearly affects the efficiency of water electrolysis: when flow velocity becomes larger, the efficiency of water electrolysis becomes higher.

In order to analyze the actual influence of the forced convection, different electrolyte flow rates $(\dot{Q})$ have been tested. The experimental data shown that when electrodemembrane distance is large ( 4 and $10 \mathrm{~mm}$ ), the flow has no effect on the potential required for the electrolysis (Fig. $5 b$ ). However, when small electrode-membrane distances are used $(0.9$ and $1.5 \mathrm{~mm})$, forced convection improves the efficiency by reducing bubbles ohmic overpotentials until a certain flow rate is reached beyond which, no significant improvements are observed (Fig. 5b).

In order to model the behaviour described above, the following equation has been proposed in this work:

$$
z=\left(z_{1}+z_{2} \cdot \dot{Q}\right) \cdot \log \left(1+\frac{\dot{Q}}{z_{4}}\right) \cdot \frac{z_{3}}{d^{2}}
$$

In (9) the constants " $z_{1}$ ", " $z_{2}$ ", " $z_{3}$ " and " $z_{4}$ " represent the influence of electrolyte flow (Q) and the electrodemembrane distance (d) in ohmic overvoltage. The term " $\left(z_{1}+z_{2} \cdot \dot{Q}\right)$ " reproduces the reduction of voltage needed in the electrolysis cell when electrolyte flow increases. The term " $\log \left(1+\dot{Q} / z_{4}\right)$ " mitigates the effect of forced convection at high flow and overrides all the equation if natural convection is used because the parameter " $\mathrm{z}$ " is zero. So the ohmic overpotentials would be defined only by " $r$ " and " $q$ ". Finally " $\mathrm{z}_{3} / \mathrm{d}^{2}$ " indicates that the electrolyte flow has a lower effect in the potential when distance between electrodes is bigger than a certain value.

Table I. Coefficients used for modelling the polarization curve.

\begin{tabular}{|c|c|c|c|}
\hline \multicolumn{2}{|l}{ COEFFICIENTS } & VALUE & UNIT \\
\hline \multirow{4}{*}{$\begin{array}{c}\text { Original Model } \\
\text { proposed by }\end{array}$} & $\mathrm{r}_{1}$ & 0.000329491987 & $\Omega \cdot \mathrm{m}^{2}$ \\
\cline { 2 - 4 } Ulleberg & $\mathrm{r}_{2}$ & -0.000002153281 & $\Omega \cdot \mathrm{m}^{2} \cdot{ }^{\circ} \mathrm{C}^{-1}$ \\
\cline { 2 - 4 } & $\mathrm{s}$ & 0.100601624017 & $\mathrm{~V}$ \\
\cline { 2 - 4 } & $\mathrm{t}_{1}$ & 114609.51467 & $\mathrm{~m}^{2} \cdot \mathrm{A}^{-1}$ \\
\cline { 2 - 4 } & $\mathrm{t}_{2}$ & -12397438.7151 & $\mathrm{~m}^{2}{ }^{\circ} \mathrm{C} \mathrm{A}^{-1}$ \\
\cline { 2 - 4 } & $\mathrm{t}_{3}$ & 409431775.5213 & $\mathrm{~m}^{2} \cdot{ }^{\circ} \mathrm{C}^{2} \cdot \mathrm{A}^{-1}$ \\
\hline \multirow{3}{*}{$\begin{array}{c}\text { Proposed model } \\
\text { in this study } \\
\text { (coefficients }\end{array}$} & $\mathrm{q}_{1}$ & -0.000131093326 & $\Omega \cdot \mathrm{m}^{2}$ \\
\cline { 2 - 4 } $\begin{array}{c}\text { added to the } \\
\text { original model) }\end{array}$ & $\mathrm{q}_{2}$ & 0.000017739286 & $\Omega \cdot \mathrm{m}^{2} \cdot \mathrm{mm}^{-1}$ \\
\cline { 2 - 4 } & $\mathrm{z}_{1}$ & -0.730 & $\Omega \cdot \mathrm{m}^{2}$ \\
\cline { 2 - 4 } & $\mathrm{z}_{2}$ & -1.4625 & $\Omega \cdot \mathrm{m}^{2} \cdot \mathrm{min}^{-1} \cdot \mathrm{l}^{-1}$ \\
\cline { 2 - 4 } & $\mathrm{z}_{3}$ & 0.000075 & $\mathrm{~mm}^{2}$ \\
\hline
\end{tabular}

\section{Optimal Operation Strategy}

The results shown in previous section indicate that the temperature, electrolyte flow and electrode-membrane distance are closely related to each other and they have a clear influence on the ohmic overpotentials in the electrolysis, especially at high current. The mathematical model presented in (4) reproduces this behaviour and it is a useful tool to predict the behaviour of an electrolyzer, especially when it is powered by RREE. Rearranging (5), $(6),(8)$ and (9) in (4), the complete model proposed is:

$$
\begin{gathered}
U=U_{\text {rev }}+\left[r_{1}+r_{2} \cdot T+q_{1}+q_{2} \cdot\left|d-d_{\text {opt }}\right|+\right. \\
\left.\left(z_{1}+z_{2} \cdot \dot{Q}\right) \cdot \log \left(1+\frac{\dot{Q}}{z_{4}}\right) \cdot \frac{z_{3}}{d^{2}}\right] \cdot i+ \\
s \cdot \log \left[\left(t_{1}+\frac{t_{2}}{T}+\frac{t_{3}}{T^{2}}\right) \cdot i+1\right]
\end{gathered}
$$

Table I contains the constants used for the modelling. The MATLAB "Non Linear Model" class was used in order to determine these coefficients. This class allows doing a non-linear regression from constants of (10), taking as input data the potential (V) and the current density $\left(\mathrm{mA} / \mathrm{cm}^{2}\right)$ from each experiment according to a procedure previously established [8].

The input variables in (10) are temperature, electrodemembrane distance, electrolyte flow rate and current density. However, in an electrolysis cell, the electrodemembrane distance is an initial design parameter, previously set during the assembly of the electrolyzer. So, this distance cannot be changed once the electrolyzer has been manufactured. On the other hand, the operating temperature in an alkaline electrolyzer is usually 60 $80^{\circ} \mathrm{C}$. Therefore, current and flow rate are the only variables to consider, once the rest of the parameters have been fixed. Since the current varies depending on the power supply used (for example, the current provided by a PV panel along a day), the key parameter to be adjusted to optimize the process is the electrolyte flow rate.
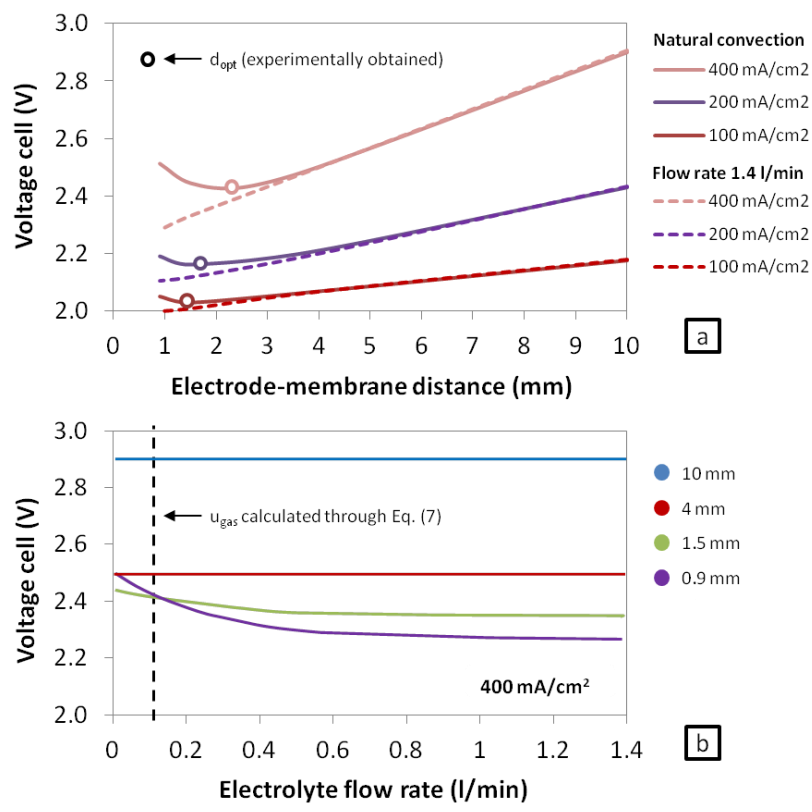

Fig. 5. Cell voltage at $50^{\circ} \mathrm{C}$ and: (a) different electrodemembrane distances, (b) different electrolyte flow rates. 
According to the experimental data obtained in this study, forced convection generally improves the efficiency of the electrolysis process. However, pumping the flow means an increase of energy supply and so a reduction of the global efficiency of the process. Nevertheless, a good method to reduce pumping energy requirements is to optimize the pump work by controlling the electrolyte flow depending of the current applied to the electrolyzer. This approach could be suitable for the typical power supply fluctuations of RREE, because one could determine the optimal flow depending of the solar irradiation or wind velocity.

Fig. 5 shows the voltage required for electrolysis at different electrode-membrane distances and flow rates. In this figure it is observed that if electrode-membrane distance $\left(\mathrm{d}>\mathrm{d}_{\mathrm{opt}}\right)$ is large, there is no significant advantage when forced convection is used.

However, when electrode-membrane distance is small $(\mathrm{d}<$ $\left.\mathrm{d}_{\text {opt }}\right)$ and natural convection is used, the voltage required for electrolysis increases (Fig. 5a). But when a flow rate of $1.4 \mathrm{l} / \mathrm{min}$ is applied, the potential diminishes. Fig. 5b shows this effect in a large range of electrolyte flow rate: an increase of flow rate reduces the voltage until reaching a flow rate value, beyond which any increase does not produce any significant improvements in the electrolysis.

Based on the results shown in Fig. 5, an optimal flow rate can be proposed $\left(\dot{Q}_{\text {opt }}\right)$ according with the current and the distance. In this way, the energy consumption can be optimized to use only the exact flow at any time:

$$
\dot{Q}_{o p t} \begin{cases}\begin{array}{l}
\text { When } d \geq d_{o p t} \Rightarrow \\
=0 l / \mathrm{min}
\end{array} & \text { in all cases } \\
\text { When } d<d_{o p t} \Rightarrow & \text { if } u_{S t} \geq u_{\text {gas }, o p t} \\
=0 l / \mathrm{min} & \text { if } u_{S t}<u_{\text {gas }, o p t} \\
=2 W d \varphi\left(u_{\text {gas opt }}-u_{S t}\right)\end{cases}
$$

Where " $\mathrm{d}_{\mathrm{opt}}$ " is calculated by (7), "W" is the width of the cell and " $\varphi$ " is an adimensional parameter obtained experimentally that indicates how much the flow rate must be increased when electrode-membrane distance is small (Fig. 5b). On the other hand, the Stokes velocity $\left(\mathrm{u}_{\mathrm{St}}\right)$ is the terminal velocity at which a bubble of density " $\rho_{\mathrm{g}}$ " and diameter " $\emptyset_{\mathrm{g}}$ " will rise in a medium (30-35 wt\% $\left.\mathrm{KOH}\right)$ of density " $\rho_{\mathrm{L}}$ " and dynamic viscosity " $\mu_{\mathrm{L}}$ " [13]:

$$
u_{S t}=\frac{1}{18} \cdot g \cdot \emptyset_{g}^{2} \cdot \frac{\rho_{L}-\rho_{g}}{\mu_{L}}
$$

Finally, " $u_{\text {gas,opt }}$ " can be calculated by (7), when the distance considered is the real electrode-membrane distance of the electrolysis cell when it was assembled.

According to (11), when the distance between electrodes is large it is not necessary to pump the electrolyte, because the gas can be distributed by a greater amount of space and new electrolyte may continuously reach the electrodes. Moreover, when current is low, the " $u_{\text {gas,opt }}$ " required is reduced by (7), and so the ascent rate of gas in the cell $\left(\mathrm{u}_{\mathrm{St}}\right)$ is enough to achieve $\mathrm{Q}_{\text {opt }}$ without forced convection.

\section{Results of the Model}

With the goal of proposing an optimized operation approach, this article reports the results corresponding to the interaction between electrolyte flow rate and electrolysis cell voltage when working with RREE. For this purpose at each moment, equations (10) and (11) must be combined following this strategy: firstly " $u_{\text {gas,opt }}$ " is calculated using (7) and the real electrode-membrane distance (d) of the electrolysis cell for the whole range of electrical currents to model. Next, " $\mathrm{u}_{\mathrm{St}}$ " is obtained by (12) with the properties of the biphasic mixture (density, viscosity and average bubble diameter, which in the experimental measurements of this study has been estimated at $180 \mu \mathrm{m})$. Finally, " $\mathrm{d}_{\mathrm{opt}}$ " is calculated by (7) considering $\mathrm{u}_{\mathrm{gas}}=\mathrm{u}_{\mathrm{St}}$ for each electrical current to model.

With the data previously calculated $\left(\mathrm{u}_{\mathrm{gas}, \mathrm{opt}}, \mathrm{u}_{\mathrm{St}}\right.$ and $\left.\mathrm{d}_{\mathrm{opt}}\right)$, the optimum flow rate is obtained $\left(\dot{\mathrm{Q}}_{\mathrm{opt}}\right)$ for each value of current in the entire range to model according to (11). By entering this value in (10), the minimum voltage can be obtained (at a constant $\mathrm{d}$ and $\mathrm{T}$ ), introducing the current and the corresponding optimum flow at all times.

\section{A. Implementation of RREE Power Supply Strategy}

To evaluate the model response using RREE, a dynamic analysis was performed by applying a current profile corresponding to a photovoltaic panel, based on actual solar profiles of different days in the city of Puertollano $\left(38^{\circ} 41^{\prime} 07^{\prime}\right.$ ' N), Spain. In order to do a wide evaluation, two different profiles were chosen (Fig. 6):

1) A profile corresponding to a sunny day, where the irradiance describes a parabola with minimum values at sunrise and sunset, and a maximum at solar midday (around 12:00-15:00).

2) A profile corresponding to a cloudy day, with a considerable degree of irradiation variability, due to fluctuations at moments of cloudiness.

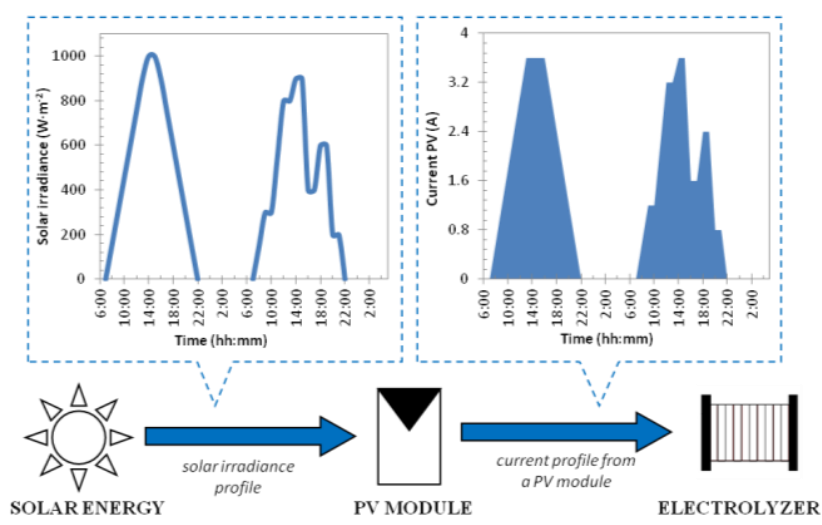

Fig. 6. Solar profile and considered response of a PV panel along a sunny and a cloudy day [8]

To perform the test with renewable energies, photovoltaic data profiles (Fig. 6) were implemented in a SCADA system, which controlled the DC power supply. As shown in Fig. 6 right, the output current of the power supply was stepped as a result of discretization performed by the SCADA system. 


\section{B. Simulation with RREE for an Optimized Operation}

In order to ensure the accuracy and validity of the proposed model, this was experimentally validated, obtaining an excellent correlation between the experimental and calculated results, as confirmed by the low average error (lower than $0.7 \%$ ). Observed trends for the different operation parameters were consistent with other studies [9], [15].

Fig. 7 shows the simulated behavior of an alkaline water electrolysis cell, in combination with RREE when it works with forced and natural convection for both PV profiles (sunny and cloudy) at $50^{\circ} \mathrm{C}$ and an electrode-membrane distance of $0.9 \mathrm{~mm}$. For the case of the sunny day (Fig. 7a), efficiency of electrolysis process increased when the electrolyte is pumped, which can be clearly observed at higher current values (higher void fraction).

The effect of the forced convection when PV energy is applied during a cloudy day is reported in Fig. 7b. Also in this case, the required potential for a high current value is lower when pump is activated. Moreover, it was observed than forced convection lightly reduced the typical fluctuations of a cloudy day PV profile, which could limit some negative effects related with RREE combination as explosive mixture formation, materials degradation, etc.

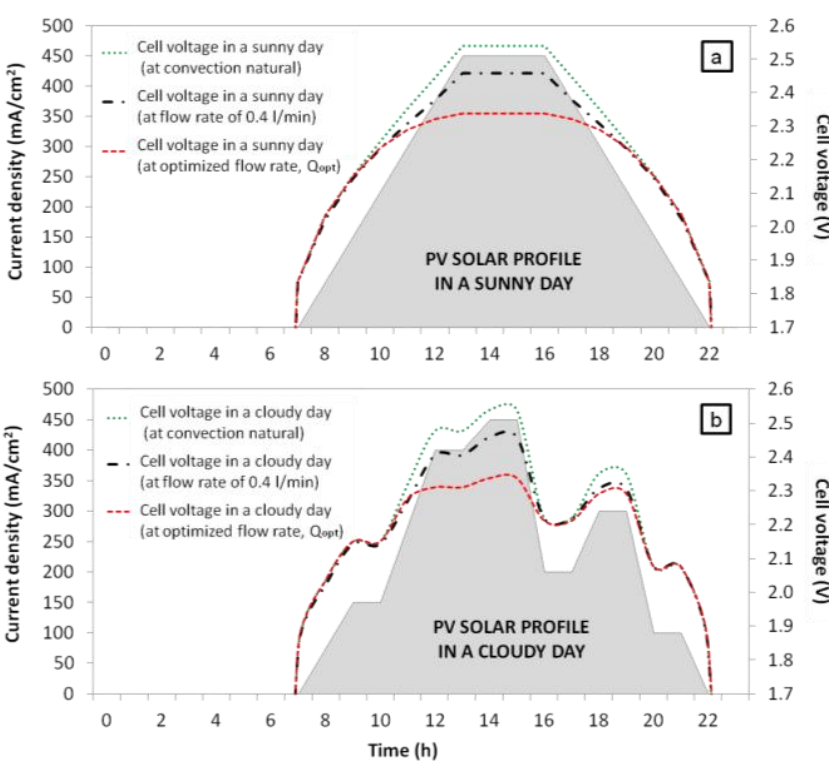

Fig. 7. Cell voltage vs. time with respect to the proposed PV profile at different flow rates for: (a) sunny day, (b) cloudy day.

The results reported in Fig. 7 also show the convenience of the optimized strategy described in this study: when the flow rate is constant (for example $0.41 / \mathrm{min}$ ), the potential is the same as in natural convection at low currents (sunrise and sunset). So to pump flow does not have any advantage in the electrolysis and the optimized flow rate will be null.

However, when the current density is high, pumping flow is a useful strategy to reduce the overpotentials. Under this condition, using the optimal flow rate for each electric current value allows reaching the minimum potential for electrolysis at all times (Fig. 7).

\section{Conclusion}

The developed model is able to reproduce the polarization curve of an alkaline electrolysis cell under different operating conditions when it is powered by renewable energy. It is a semiempyrical model based on experimental data. Through this model, it can be established an optimal operating strategy for hydrogen production varying the electrolyte flow rate, when the electrolyzer is powered by PV solar energy, in order to minimize the potential required in electrolysis.

\section{Acknowledgement}

This work has been developed in Centro Nacional del Hidrógeno (www.cnh2.es) whose financial supporters are MINECO (Spain), JCCM (Spain) and ERDF.

\section{References}

[1] M. Ball and M. Wietschel, "The future of hydrogen opportunities and challenges", in Int J Hydrogen Energy 2009, Vol. 34(2), pp. 615-627

[2] D. Pletcher, and X. Li, "Prospects for alkaline zero gap water electrolysers for hydrogen production", in Int J Hydrogen Energy 2011, Vol. 36(23), pp.15089-15104.

[3] Ø. Ulleberg, T. Nakken and A. Eté, "The wind/hydrogen demonstration system at Utsira in Norway", in Int J Hydrogen Energy 2010, Vol. 35(5), pp. 1841-1852.

[4] Ø. Ulleberg, "Modeling of advanced alkaline electrolyzers: a system a system simulation approach", in Int J Hydrogen Energy 2003, Vol. 28(1), pp. 21-33.

[5] J.O. Jensen, V. Bandur, N.J. Bjerrum, S.O. Jensen, S. Ebbesen, M. Mogensen M et al. "Pre-investigation of water electrolysis", in PSO-F\&U 2006-1-6287.

[6] J. Divisek and H. Schmitz, "A bipolar cell for advanced alkaline water electrolysis", in Int J Hydrogen Energy 1982, Vol. 7(9), pp. 703-710

[7] N. Nagai, M. Takeuchi and M. Nakao, "Influences of bubbles between electrodes onto efficiency of alkaline water electrolysis", in Proc. PSFVIP-4 2003.

[8] E. Amores, J. Rodríguez and C. Carreras, "Influence of operation parameters in the modeling of alkaline water electrolyzers for hydrogen production", in Int J Hydrogen Energy 2014, Vol. 39(25), pp. 13063-13078.

[9] L.M. Gandía, G. Arzamendi and P.M. Diéguez, "Renewable hydrogen technologies: production, purification, storage, applications and safety", Elsevier, Amsterdam (2013).

[10] K. Zeng and D. Zhang, "Recent progress in alkaline water electrolysis for hydrogen production and applications", in Prog Energy Combust Sci 2010, Vol. 36(3), pp. 307-326.

[11] D.M.F. Santos, C.A.C. Sequeira and J.L. Figuereido, "Hydrogen production by alkaline water electrolysis", in Quím Nova 2013, Vol. 36(8), pp. 1176-1193.

[12] M. Takeuchi and T. Furtua, "Efficiency and two-phase flow of alkaline water electrolysis under forced convection of electrolyte", in Int Heat Transfer Conference 2006.

[13] J. Schillings, O. Doche and J. Deseure, "Modeling of electrochemically generated bubbly flow under buoyancydriven and forced convection", in Int $\mathrm{J}$ of Heat and Mass Transfer 2015, Vol. 85, pp. 292-299.

[14] N. Nagai, M. Takeuchi and T. Furuta, "Effects of bubbles between electrodes on alkaline water electrolysis efficiency under forced convection of electrolyte", in WHEC 2006.

[15] N. Nagai, M. Takeuchi, T. Kimura and T. Oka, "Existence of optimum space between electrodes on $\mathrm{H}_{2}$ production by water electrolysis", in Int J Hydrogen Energy 2003, Vol. 28, pp. 35-41. 